\title{
Between strategy and protest: how policy demand, political dissatisfaction and strategic incentives matter for far-right voting
}

\author{
Denis Cohen* \\ Mannheim Centre for European Social Research, University of Mannheim, Mannheim, Baden-Württemberg, Germany \\ ${ }^{\star}$ Corresponding author. E-mail: denis.cohen@mzes.uni-mannheim.de
}

(Received 30 October 2017; revised 12 October 2018; accepted 20 October 2018; first published online 10 June 2019)

\begin{abstract}
What attracts voters to far-right parties? Emphasizing the repercussions of far-right parties' past achievements on the mobilization of voters' electoral demand, this paper develops an argument of contextdependent strategic far-right voting. Far-right parties seek to mobilize on a combination of demand for nativist policies and anti-establishment protest sentiment. Their capacity of doing so, however, critically depends on the strategic incentives they supply. My findings from a comparative analysis based on six waves of the European Election Study show that far-right parties' past attainment of legislative strength boosts the credibility of their policy appeal and broadens the scope of their protest appeal whereas their participation in government jeopardizes their capacity to mobilize on popular discontent.
\end{abstract}

Keywords: Comparative politics; political behavior; European politics and integration; political parties and interest groups; voting behavior

\section{Introduction}

Far-right parties have competed in the electoral arenas of many Western European countries for multiple decades. Yet, recent years have seen far-right competitors attract unparalleled levels of electoral support. In the 2014 European parliamentary elections, far-right parties came out as the frontrunners in numerous countries. UKIP successfully mobilized voters for the "Brexit" vote in the 2016 British EU referendum. Austria and France saw far-right competitors enter the runoff stages of their presidential races in 2016 and 2017, respectively, and the 2017 German Federal Election saw a far-right party enter the Bundestag for the first time in the history of the Federal Republic.

These events have spawned renewed interest in explanations of the electoral appeal of the far right. Extant research typically falls into one of two categories. Demand-side inquiries focusing on voter behavior highlight political attitudes and preferences. Numerous contributions have prominently analyzed the roles of policy-directed considerations and political dissatisfaction in explaining far-right voting (e.g., Van der Brug et al., 2000; Van der Brug and Fennema, 2003; Norris, 2005; Arzheimer, 2008; Ivarsflaten, 2008; Schumacher and Rooduijn, 2013; Van Hauwaert and van Kessel, 2018). Inquiries focusing on parties and party competition, on the other hand, focus on political supply, highlighting far-right parties' agency within the constraints of their competitive environments (e.g., Carter, 2005; Norris, 2005; Van der Brug et al., 2005; Arzheimer, 2009; Art, 2011).

While both strands of research critically help us understand when and why far-right parties attract voters, they tend to remain poorly connected. This is unfortunate because varying contexts

(C) The European Political Science Association 2019. This is an Open Access article, distributed under the terms of the Creative Commons Attribution licence (http://creativecommons.org/licenses/by/4.0/), which permits unrestricted re-use, distribution, and reproduction in any medium, provided the original work is properly cited. 
of party competition are likely to exert critical repercussions on the translation of attitudinal demand into individual voting behavior-which can in turn explain variations in the far right's electoral appeal in terms of both strength and kind. Following recent contributions that point out the necessity of taking into account the interplay of demand and supply (Mudde, 2010; Van Kessel, 2015), I present a theoretical argument and a comparative test that emphasize how farright parties' past achievements convey context-dependent electoral incentives, which critically condition how-and how strongly—-far-right parties appeal to voters.

Far-right parties offer an ideological package deal: They combine a distinctive positional policy platform with a pronounced anti-establishment stance. They thereby appeal to voters who agree with their policy platform as well as to voters who are dissatisfied with the political establishment. Voters, however, also evaluate the credibility of far-right parties' policy and anti-establishment appeals and strategically discount the two components when they anticipate that far-right parties fail to deliver on their appeals. I argue that far-right parties' past achievements systematically condition the role of policy demand and political dissatisfaction for individual voting behavior: Far-right parties' previous success conveys important and possibly divergent strategic incentives for voting on policy demand and political dissatisfaction in voters' future-oriented electoral considerations. Far-right parties' ability to influence policy becomes more credible as they gain legislative strength, and hence voting on policy demand intensifies. At the same time, attaining legislative success does limited harm to far-right parties' anti-establishment credentials-as long as they remain in opposition. By joining forces with mainstream parties in government, in contrast, far-right parties jeopardize their appeal to politically dissatisfied voters.

I present a systematic comparative test of this theoretical framework. In order to test how policy demand, political dissatisfaction, and strategic incentives structure far-right voting, I use a comprehensive data set based on six waves of the European Election Study. The sample covers nearly 50,000 individuals from 11 West European polities over up to 25 years between 1989 and 2014. My findings from Bayesian hierarchical models lend strong support to the theoretical expectations. Among oppositional far-right parties, legislative strength boosts the relevance of policy-directed voting without undermining their anti-establishment appeal. To the contrary, stronger far-right parties even manage to broaden the scope of their protest appeal. Far-right parties in government, on the other hand, fail to appeal to politically dissatisfied voters. Instead, voters are exclusively attracted by policy-directed considerations. These findings highlight important systematic interrelations between individual electoral demand and party-specific political supply and bear important implications for the study of voting behavior and electoral outcomes in Western democracies.

\section{Theoretical framework}

\subsection{Far-right parties and far-right voting}

Far-right parties share a characteristic ideological feature: At its core, their platform is based on a positional policy appeal. This core is supplemented and combined with an anti-establishment appeal: Far-right parties cast themselves as a pariah party and as the true defender of the popular interest against the corrupt establishment (e.g., Mudde, 2007; Van Kessel, 2015). ${ }^{1}$ Consequently, voters may be attracted to far-right parties on the basis of two distinct motives: Demand for the representation and implementation of the core policies that far-right parties campaign on and dissatisfaction with the political establishment.

\footnotetext{
${ }^{1} \mathrm{My}$ conceptualization and selection of far-right parties follows an inclusive approach similar to that presented in Art (2011). In contrast to recent contributions which focus on a specific subset of far-right parties, the populist radical right (e.g., Mudde, 2007), I include parties defined by a nativist ideology and by an anti-establishment platform. This allows for the inclusion of both populist nativist parties and nativist parties that do not explicitly endorse people-centrism or (populist) democracy.
} 
Contributions that emphasize the role of policy demand in far-right voting usually adopt the premises of proximity theories (Downs, 1957; Enelow and Hinich, 1984; Van der Brug et al., 2000): Voters favor those parties that campaign on policies and issue positions that are closest to their substantive preferences. Notions of "pure" protest voting, on the other hand, view farright voting as an instrumental act independent of policy-directed considerations. According to this perspective, politically dissatisfied voters act out of the rational desire to punish the incumbent elites or to protest against the political system which the established parties epitomize (Fennema, 1997; Van der Brug et al., 2000). Hence, a "pure" protest voter votes for far-right parties exclusively out of dissatisfaction with the establishment. An alternative perspective views protest motives as a supplementary factor to policy demand in explaining voting behavior. According to this view, policy-directed voting and protest voting are not mutually exclusive. Instead, they are distinct motives for supporting populist and anti-establishment parties. Over and beyond their policy preferences, voters who hold disdainful attitudes toward the political establishment and mainstream politics can be attracted by the antagonistic anti-establishment appeals of far-right parties (e.g., Akkerman et al., 2013; Van Hauwaert and van Kessel, 2018). Far-right voters may therefore act out of a single (i.e., policy-directed or protest) motive-or out of both at once.

Empirical analyses of far-right voting behavior have vastly rejected the notion that vote choices for far-right parties were exclusively driven by protest motives. While many inquiries show that far-right voting is predominately motivated by the demand for the far right's policies, either in terms of general left-right positions (Van der Brug et al., 2000; Van der Brug and Fennema, 2003) or restrictive immigration preferences (Arzheimer, 2008; Ivarsflaten, 2008), several contributions point out that electoral demand for far-right parties is in fact co-determined by policydirected considerations and political dissatisfaction (e.g., Arzheimer, 2008; Ivarsflaten, 2008; Schumacher and Rooduijn, 2013). As a persistent and yet puzzling finding, these studies show considerable heterogeneity in the effects of both policy demand and political dissatisfaction on far-right voting across electoral contexts. This indicates that the relative and absolute strength of far-right parties' policy and anti-establishment appeals varies widely. The crucial question, then, is how these differences can be explained.

Several studies have argued that party-specific cues condition the extent of policy-directed voting. Van der Brug et al. (2000) and Van der Brug and Fennema (2003), drawing on previous work by Tillie (1995), distinguish idealistic from pragmatic voters: The former vote for a party solely due to agreement with its policy, whereas the latter concurrently take into account the parties' strength and influence in the legislature. Empirically, however, these studies do not fully capitalize on this distinction. Given the small number of far-right parties included in Van der Brug et al. (2000) and Van der Brug and Fennema (2003), these studies cannot systematically test whether the relevance of policy-directed considerations for far-right voting is increasing in farright parties' strength. In contrast, Bos and van der Brug (2010) provide a direct test of strategically conditioned policy-directed voting. They show that subjective perceptions of party (leader) effectiveness and legitimicacy elevate the effect of policy preferences on party evaluations (see also Bos et al., 2011). Similar findings with respect to stigmatizing news coverage of far-right parties by Van Spanje and Azrout (2018) corroborate the notion that policy-directed voting is contingent on strategic considerations. The use of innovative measures in these studies, however, comes at the cost of limited empirical scope: The studies focus on a maximum of two Dutch farright parties in single electoral contexts. While extant research on far-right voting has thus embraced the idea that strategic considerations condition the scope of policy-directed far-right voting, we still lack a broad comparative test.

Furthermore, arguments on strategic cues in far-right voting have so far been confined to policy-directed considerations and hardly address the considerable contextual variation in the relevance of political dissatisfaction for far-right voting. Van Spanje (2011) suggests that anti-establishment parties lose disproportionately following government involvement for "keeping the rascals in": They alienate anti-establishment voters by helping mainstream parties stay in 
power. Yet, the findings from his party-level analysis cannot establish an underlying micro-logic: Government involvement may harm anti-establishment parties either by damaging the credibility of their anti-establishment appeal or by damaging their credibility of delivering on their policy appeal-e.g. due to unpopular concessions to their coalition partners or for demonstrating incompetence to govern (e.g., Heinisch, 2003; Akkerman and De Lange, 2012; Afonso, 2015). This suggests that the distinction between government and opposition may critically change the electoral incentives that far-right parties supply both for voting on policy demand and for voting on political dissatisfaction. Given the increasing number of instances of far-right government involvement since the late 1990s, we should thus compare the electoral appeal of far-right parties not only in terms of their strength in parliament but also in terms of their government status.

While the extant literature has thus repeatedly touched upon the effects of far-right agency on the mode and strength of their appeal, we still lack a comprehensive argument and a comparative test. To address these shortcomings, I present a comprehensive theoretical framework for studying the repercussions of far-right government involvement and legislative strength on the micrologic of far-right support.

\subsection{Policy demand, political dissatisfaction, and strategic incentives}

Much of the comparative literature on far-right parties' electoral and political success focuses on their agency within the opportunities and constraints posed by their political environments. My argument, in contrast, turns around the telescope and investigates the repercussions of far-right parties' past achievements on the micro-level mechanisms by which they mobilize support. I argue that far-right parties' past attainments of legislative strength and government involvement ${ }^{2}$ convey systematic and potentially divergent signals for the credibility of their policy and anti-establishment appeals. This, in turn, affects voters' prospective evaluations of these paties and systematically conditions how-and how strongly-voters are attracted to them.

My argument follows the basic logic of discounting theory (Grofman, 1985): Voters' do not just naively consider parties' nominal platforms but also how credibly parties can deliver on their ideological appeals. ${ }^{3}$ As far-right parties campaign on a twofold ideological platform defined by policy and anti-establishment appeals, voters simultaneously scrutinize the credibility of both components: They discount the policy appeal when they anticipate that far-right parties are incapable of influencing the legislative agenda and assign less weight to the anti-establishment appeals when far-right parties fail to take a credible antagonistic stance toward established parties. Rather than focusing on general contextual determinants of electoral support for far-right parties (e.g., Van der Brug et al., 2005; Carter, 2005; Arzheimer, 2009), my argument thus emphasizes systematic repercussions of far-right parties' past attainments on the formation of future vote intentions at the individual level.

First, in line with existing arguments of strategic voting (e.g., Downs, 1957; Cox, 1997; Van der Brug et al., 2000), I expect that oppositional far-right parties with a strong standing in the national parliament offer pronounced strategic incentives for policy-directed voting. This is because stronger far-right parties are more likely to influence the political agenda from the opposition benches. They may do so by a number of mechanisms: A strong presence in national parliament boosts parties' visibility in the media and systematically strengthens their ability to raise the salience of their core issues and issue positions. This, in turn, affects the issue attention and

\footnotetext{
${ }^{2}$ By "in opposition", I refer to parties in both intra-parliamentary and extra-parliamentary opposition. By "in government", I refer to (junior) coalition partners as well as formal supporters of minority cabinets.

${ }^{3}$ In line with extant rational theories of voting (e.g., Downs, 1957; Cox, 1997), I assume that voters are instrumental actors whose evaluations of political parties follow a latent utility logic: Regardless of their eventual vote choice, voters evaluate the electoral attractiveness of a given party based on ideological and strategic considerations.
} 
issue positions of mainstream parties as well as policy outcomes (Meguid, 2005; Van Spanje, 2010a; Wagner and Meyer, 2017). Strategic voters are attentive to these incentives. The more they believe that a party can deliver on its policy platform, the more weight they assign to policydirected considerations in evaluating the prospect of voting for the party. In contrast, voters who are pessimistic about a party's ability to leverage the issues and issue positions that it campaigns on will likely discount its policy appeal. Despite the high agreement with the parties' policies, they may not risk voting for a party that remains electorally irrelevant and vote for a more powerful alternative instead.

Conditional on sufficient legislative strength, far-right parties may also be able to join government (De Lange, 2012). This represents a unique context in which voters likely evaluate the party primarily in terms of its performance instead of in terms of its strength. Whether government involvement strengthens or hampers the policy appeal of far-right parties is ambiguous. On the one hand, government involvement offers parties a direct avenue for implementing policies and thereby much greater opportunities for delivering on their core promises than opposition. On the other hand, it also brings about the necessity of making policy concessions to their partners. Furthermore, internal strife over the challenges of government may lower the parties' valence and thereby lead voters to doubt whether the party can effectively promote its programmatic stances (Heinisch, 2003; Akkerman and De Lange, 2012; Zaslove, 2012). Far-right government involvement may thus convey counteracting incentives for policy-directed voting. I therefore expect that, on average, far-right parties in government attract voters on policy demand at comparable levels as they would have done in opposition.

Next, I discuss the implications of legislative strength for the relevance of protest motives. On the one hand, one might expect that stronger and more successful far-right parties are less likely to appeal to dissatisfied voters. Attaining and maintaining legislative strength usually requires initial efforts toward internal consolidation and professionalization (Art, 2011). ${ }^{4}$ This typically comes with a stronger reliance on vote- and office-seeking strategies: To reach out to broader segments of the electorate, far-right parties strategically moderate extreme policy positions and place greater emphasis on policy appeals vis-à-vis anti-establishment messages (e.g., Art, 2011; Rooduijn et al., 2014). As a result, they are confronted with less political ostracism (Van Spanje, 2010b; De Lange, 2012). Consequently, stronger far-right parties could fail to credibly set themselves apart from the political establishment.

The process of attaining and maintaining legislative leverage demands a balancing actappealing to wider segments of the electorate while "maintaining the integrity of their populist and radical right identity" (Zaslove, 2012, 444). Yet, far-right parties in opposition have sufficient leeway to do so successfully. Many far-right parties strategically combine broadly appealing stances on salient policy issues with a milder, non-extremist populist stance. Thereby, they can successfully foster the credibility of their policy appeal while maintaining the credibility, and possibly broadening the scope, of their anti-establishment appeal (Van Kessel, 2015). Hence, I expect that irrespective of their legislative strength, far-right parties in opposition maintain a credible anti-establishment appeal and therefore consistently attract politically dissatisfied voters.

Far-right parties in government, on the other hand, face liabilities that likely jeopardize a credible compromise between pronounced opposition to the establishment and an effective pursuit of substantive policies. As coalition partners of center-right parties, bound to coalition agreements and under pressure to deliver as policy makers, they are unlikely to credibly cater for popular protest sentiment. Voters who want to denounce the political establishment and oust them from power will not consider them a viable means toward these ends. Among the various explanations why far-right government involvement may alienate voters-unpopular policy concessions (Afonso, 2015), incompetence to govern (Heinisch, 2003; Akkerman and De Lange, 2012), or joining forces with the political establishment (Van Spanje, 2011) - the last one therefore likely

\footnotetext{
${ }^{4} \mathrm{~A}$ rare but nonetheless important exception is the so-called flash parties (Art, 2011).
} 
sketches the most important behavioral mechanism. Over and beyond the costs and benefits to the credibility of far-right parties' policy appeal, government involvement thus decisively harms the credibility of their anti-establishment appeal. Therefore, I expect political dissatisfaction to be of limited to no relevance in voting for far-right parties in government.

\section{Empirical strategy}

\subsection{Data and operationalization}

Empirical tests of the hypotheses laid out above require a broad sample of heterogeneous contexts under which prospective vote intentions take shape. I pool data from the 1989 to 2014 waves of the quinquennial European Election Study (EES) for 11 West European polities. Western Europe constitutes an ideal arena for analysis because the relative stability of its party systems ensures that parties' past performances can signal valid strategic incentives for future-oriented voting. The resulting sample comprises 48,404 respondents nested in 47 different political contexts.

Table 1 offers a full overview of all available countries, parties, and time points. Due to the inclusion of multiple far-right parties in some political contexts, the sample allows for the analysis of individual evaluations of a total of 52 far-right parties, 45 of which were in opposition and seven of which were in government at the time of the survey.

\subsubsection{Dependent variable}

A decisive benefit of the EES is the consistent inclusion of party-specific probability of future vote (PTV) items. This question prompts respondents to disclose how probable they consider it to ever vote for a given party-regardless of their discrete vote intention. This measure critically facilitates analyses of voting behavior for small parties for which only negligible numbers of respondents report a discrete vote recall or vote intention (Van der Eijk et al., 2006). It thereby allows for studying vastly heterogeneous choice contexts, featuring weak and strong far-right parties alike. I interpret subjective probabilities of future voting for a given far-right party as evaluations of the far right's electoral attractiveness at the time of the survey. ${ }^{5}$ I rescale the original 1-10 (1989-2004) and 0-10 (2009-2014) scales to the unit scale. Many respondents categorically negate the possibility of ever voting for the far right, resulting in a large point mass ( $>60$ percent) at zero. I address this distributional characteristic in more detail in one of the following sections.

\subsubsection{Main predictors}

To operationalize respondents' policy demand for a given far-right party's policy platform, I compute Euclidean distances between voters' left-right self-placement, $v_{i}$, and their subjective placement of the far-right party in question on the left-right scale, $p_{i j}$. I rescale both metrics such that they range from 0 to 1 , which yields a measure of policy distance on the unit interval: dist ${ }_{h}=\mid v_{i}-$ $p_{i j}$, where subscript $h$ denotes a given voter-party dyad. A well-known problem in relying on subjective party placements is party position rationalization bias: Voters' party preferences may determine how close they place parties to their own ideal points, leading to upward-bias in the effect of policy proximity. I follow Weber's (2015) procedure to estimate and correct for party position rationalization and report a corresponding robustness check in the Online Appendix.

Detailed and consistent measures of political dissatisfaction are relatively rare in surveys with the broad spatio-temporal coverage required to address my research question. While recent

\footnotetext{
${ }^{5} \mathrm{~A}$ common caveat against the interpretation of PTV scores as utility metrics is that numerical values representing subjective vote probabilities may not be inter-subjectively equivalent. Individuals reporting the same probability of voting for a party may have different inclinations of actually doing so depending on the probabilities they assign to the other available alternatives. I address this problem in a robustness check explicated in the Online Appendix using a normalized PTV metric.
} 
Table 1. Post-imputation sample based on EES 1989-2014

\begin{tabular}{|c|c|c|c|c|c|c|c|}
\hline Country & 1989 & 1994 & 1999 & 2004 & 2009 & 2014 & Total (Country) \\
\hline \multirow[t]{2}{*}{ Austria } & & & FPÖ & $\mathrm{FPÖ}^{(g)}$ & FPÖ & FPÖ & 3625 \\
\hline & & & & & BZÖ & BZÖ & \\
\hline Flanders & & VB & VB & & VB & VB & 1989 \\
\hline Wallonia & & FNb & $\mathrm{FNb}$ & & FNb & & 1127 \\
\hline \multirow[t]{2}{*}{ Denmark } & FrP & FrP & FrP & & & & 6403 \\
\hline & & & DF & $\mathrm{DF}^{(g-)}$ & $\mathrm{DF}^{(g-)}$ & DF & \\
\hline Finland & & & PS & PS & PS & PS & 5528 \\
\hline France & $\mathrm{FN}$ & $\mathrm{FN}$ & $\mathrm{FN}$ & $\mathrm{FN}$ & $\mathrm{FN}$ & FN & 9430 \\
\hline Germany & $\operatorname{REP}^{(w)}$ & $\operatorname{REP}^{(w)}$ & REP & REP & & AfD & 5528 \\
\hline \multirow[t]{2}{*}{ Italy } & MSI/AN & $\mathrm{MSI} / \mathrm{AN}^{(g)}$ & & & & & 9430 \\
\hline & & $\mathrm{LN}^{(g)}$ & $\mathrm{LN}$ & $\operatorname{LN}^{(g)}$ & $\mathrm{LN}^{(g)}$ & LN & \\
\hline Netherlands & & $C D$ & $C D$ & LPF & PVV & PVV & 5698 \\
\hline Sweden & & & & & SD & SD & 2146 \\
\hline \multirow[t]{2}{*}{ UK } & & & & & UKIP & UKIP & 2421 \\
\hline & & & & & BNP & & \\
\hline Total (Year) & 4253 & 6157 & 9232 & 8368 & 9009 & 11385 & 48404 \\
\hline
\end{tabular}

${ }^{(g)}$ In government coalition. ${ }^{(g-)}$ Formally supporting minority government. ${ }^{(w)}$ West German sample only.

contributions have introduced sophisticated measures of populist and anti-establishment attitudes (e.g., Akkerman et al., 2013; Schumacher and Rooduijn, 2013; Rooduijn et al., 2016), I thus rely on simpler indicators of political dissatisfaction. For the 1989-2009 waves of the EES, I make use of an item prompting respondents to rate how satisfied they were with the way democracy worked in their country. In the 2014 wave, this item was replaced with the question whether respondents believed their voice counted in their country. Both items are measured on similar ordinal scales. ${ }^{6}$ To facilitate the interpretation of my findings, I treat the variable as continuous and rescale it to range from 0 (indicating high political satisfaction) to 1 (indicating high dissatisfaction). Since the two items are not fully equivalent, I conduct a robustness check on a 1989-2009 subsample to ensure that this inconsistency in measurement does not critically drive my findings.

To operationalize far-right parties' legislative strength, I use their share of seats in the national legislature determined at the last national election preceding the survey. This measure has been frequently used to capture strategic voting in studies focusing on far-right parties and beyond (e.g., Van der Brug et al., 2000; Van der Brug and Fennema, 2003; Franklin and De Sio, 2012) and allows for a parsimonious and cross-nationally applicable operationalization of electoral incentive structures. Alternatively, one may argue that in general elections held under disproportional electoral rules, electorally strong far-right parties with few to no seats in parliament may provide similar strategic incentives, e.g. by setting the political agenda and influencing mainstream parties during electoral campaigns (Meguid, 2005). Voters may also update their beliefs on parties' strength and effectiveness in response to more recent events, such as European Parliament elections or shifts in national polls. I, therefore, present a series of corresponding robustness checks in the Online Appendix. Additionally, the Online Appendix reports a replication of my analysis using data from the European Social Survey 1-8. Despite trade-offs with respect to the dependent variable and temporal coverage, the ESS allows me to test my argument using more refined measures to capture the concepts of policy demand and dissatisfaction with the political establishment: Voters' immigration preferences and their trust in politicians.

\footnotetext{
${ }^{6}$ Responses to the 2014 item tend to portray a slightly lower mean and slightly larger between- and within-country variation than responses to the former question between 1989 and 2009. These differences are however mild and correspond in magnitude to differences in means and variances of the first measure across countries and survey waves between 1989 and 2009.
} 


\subsubsection{Control variables}

I control for a set of socio-demographic indicators including age (in years, linear and squared terms), gender and education. Owing to data availability, I capture different levels of educational attainment by the age at which individuals left full-time education (below age 16, between age 16 and 19, and after age 19). Additionally, I control for two indicators that are popular explanations for center-right and center-left party support in socio-structural models of voting behavior: Individuals' religiosity, captured by an ordinal measure of their frequency of church attendance, and whether individuals live in a union household. Additional attitudinal predictors are not included as these are likely endogenous to the ideological predictors already included in the analysis. $^{7}$

\subsection{Model and estimation}

Subjective probabilities of future voting for a given party have typically been accommodated in linear models (e.g., Van der Brug et al., 2000; Van der Eijk et al., 2006). This is, however, problematic in analyses focusing on smaller and more polarizing parties such as those of the Western European far-right. As the bulk of respondents disclose that they consider it not at all probable to ever vote for a far-right party, the variable is heavily inflated with point mass at zero. In order to account for this distributional property, I treat individual responses to the PTV question as if they followed a left-censored process. I assume that individuals hold latent (i.e., unobserved) evaluations of far-right parties' electoral attractiveness, $\mathrm{ptv}_{h}{ }^{*}$, which may extend into negative values. Individuals with non-positive evaluations of a given party's electoral attractiveness then report they consider it "not at all probable" to ever vote for it whereas individuals with positive evaluations report the observed survey response: ${ }^{8}$

$$
\begin{array}{r}
\mathrm{ptv}_{h}=0 \text { if } \mathrm{ptv}_{h}^{*} \leq 0 \\
\mathrm{ptv}_{h}=\mathrm{ptv}_{h}^{*} \text { if } \mathrm{ptv}_{h}^{*}>0
\end{array}
$$

An empirical test of the implications of my theoretical framework calls for a comparative assessment of the relevance of policy demand and political dissatisfaction for far-right voting. According to my theory, the respective relevance of these variables is conditioned by strategic incentives that stem from the political context. I have argued that for the vastly heterogeneous group of oppositional far-right parties, parties' strength exerts important repercussions on policydirected voting. Among the more homogeneous group of far-right parties in government, in contrast, these incentives stem exclusively from the fact that these parties hold office: I have argued that this should first and foremost jeopardize their anti-establishment appeal, and thereby depress the relevance of political dissatisfaction. I thus model differences in the effects of policy demand and political dissatisfaction between far-right parties in opposition and far-right parties in government per separate models (inequations (1) and (2), respectively) and contextually induced differences in these effects within the former group per interaction effects of micro-level demand and far-right strength in equation (1). This allows me to retrieve distinct estimates of the relevance of policy demand and political dissatisfaction for far-right voting among oppositional parties at varying levels of their legislative strength on the one hand and for far-right parties in

\footnotetext{
${ }^{7}$ I account for missing data points on the selected variables using multiple imputation. I provide general summary statistics with information on missingness for each variable and a description of the imputation procedure in the Online Appendix.

${ }^{8}$ The substantive conclusions of my analysis do not hinge on this assumption and hold under different model specifications. See Figures A.2 and A.3 in the Online Appendix.
} 
government on the other.

$$
\begin{aligned}
\operatorname{ptv}_{h}^{*}= & \beta_{0 j}+\beta_{1} \text { dist }_{h}+\beta_{2} \text { dissatisfact }_{i}+\beta_{3} \text { seat share }_{j} \\
& +\beta_{4} \text { dist }_{h} \times \text { seat share } \\
j & +\beta_{5} \text { dissatisfact }_{i} \times \text { seat share }_{j} \\
& +\mathbf{x}_{i}^{\prime} \boldsymbol{\gamma}+v_{i}+\epsilon_{h} \\
\operatorname{ptv}_{h}^{*} & =\beta_{0 j}+\beta_{1} \text { dist }_{h}+\beta_{2} \text { dissatisfact }_{i}+\mathbf{x}_{i}^{\prime} \boldsymbol{\gamma}+v_{i}+\epsilon_{h}
\end{aligned}
$$

Individual-specific control variables are captured by the vector $\mathbf{x}_{i}$. I model differences in aggregate vote inclinations for the far right across choice contexts through heterogeneous intercepts, $\beta_{0 j}$. In equation (1), these are modeled as random intercepts that vary by choice contexts. Due to the small number of contexts in the model described in equation (2), I model heterogeneity in $\beta_{0 j}$ by discrete intercepts akin to a "fixed-effects" approach. Whenever political contexts feature multiple far-right parties, the analysis includes multiple observations per individual. To account for the dependence among these, the models feature a random effect, $v_{i}$. This captures individualspecific idiosyncrasies when multiple observations per individual are analyzed while assigning a joint intercept to all remaining observations.

I implement and estimate these models in a Bayesian framework using Stan. ${ }^{9}$ Stan uses Hamiltonian Monte Carlo sampling, which is known for its fast convergence to the target distribution (Stan Development Team, 2016). I run sets of two Markov chains across $M=5$ multiply imputed data sets. Each chain is run for a total of 2,000 draws of which I discard the first 1,000 as warm-up. This yields a total of $S=10000$ posterior draws. I check for convergence within each set of chains across the imputations and consider chains to have converged when the Gelman-Rubin diagnostic remained below 1.1 .

\section{Results}

For an empirical assessment of my theoretical expectations, I present two quantities of interest. Average marginal effects indicate the relevance of policy demand and political dissatisfaction for voters' evaluations of far-right parties under varying contextual incentive structures. Conditional expected values of subjective vote probabilities provide complementary illustrations of the intensity of the context-dependent electoral appeal of far-right parties at specified levels of policy demand and political dissatisfaction. They thereby reveal how far-right parties mobilize support under different political contexts. ${ }^{10}$

Figure 1 reports conditional average marginal effects of policy distance and political dissatisfaction on subjective vote probabilities for the far right. Each quantity is reported separately for far-right parties in opposition (on the left-hand side) and for far-right parties in government (on the right-hand side). I first turn to far-right parties in opposition. The upper left of Figure 1 shows that the importance of policy demand for far-right voting increases strongly in the far right's legislative strength. As far-right seat shares increase from 0 percent to the observed maximum of 23 percent, the marginal effect of policy distance changes from $-0.28[-0.35,-0.22]$ to $-0.61[-0.72,-0.49]$. In line with theories of strategic voting, this shows that parties' strength conveys incentives that boost the relevance of policy-directed considerations for voting behavior: When voters feel that a party can credibly deliver on its promises, they assign greater weight to the substantive platform that the party campaigns on.

\footnotetext{
${ }^{9}$ Full model specifications, including my prior specifications and weighting scheme, can be found in the Online Appendix.

${ }^{10}$ Details on the calculation of these quantities of interest as well as tables reporting the regression estimates are reported in the Online Appendix.
} 

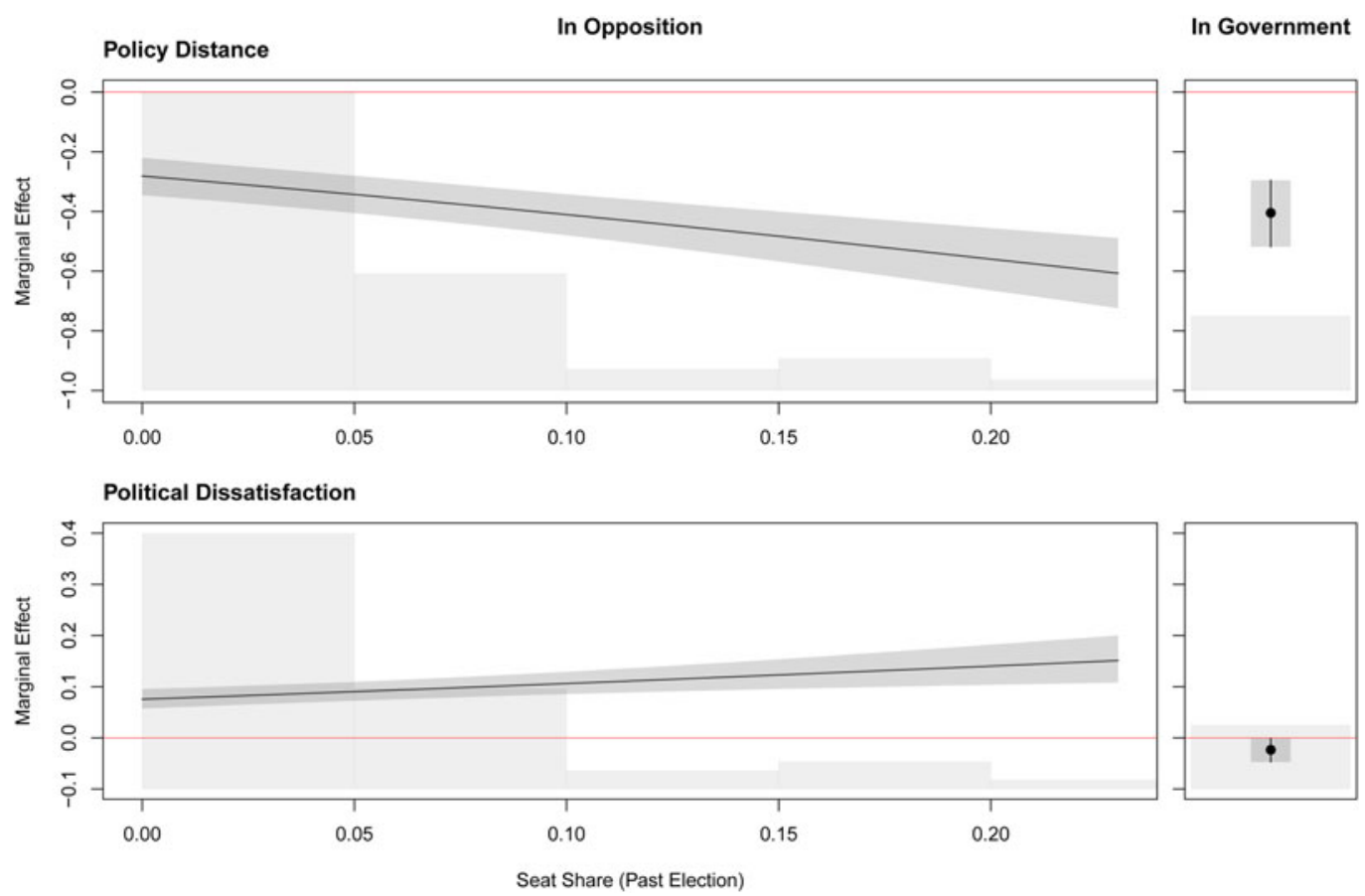

Figure 1. Average marginal effects of policy distance and political dissatisfaction for far-right parties in opposition and far-right parties in government. Note: Posterior medians and 95\% posterior intervals.

The marginal effect of political dissatisfaction, displayed in the lower left of Figure 1, increases slightly as the far right's legislative strength increases, going from $0.08[0.06,0.10]$ where far-right parties are weak to $0.15[0.11,0.20]$ where they are strong. This shows that far-right success alone, often accompanied by processes of internal consolidation and professionalization, does not undermine the credibility of their protest appeal. To the contrary, as long as far-right parties are in opposition, prior success allows them to broaden the scope of their appeal to dissatisfied voters. ${ }^{11}$ These findings thus lend strong support to my theoretical expectations.

For far-right parties in government, voter evaluations are markedly driven by policy-directed considerations. As displayed in the upper right of Figure 1, the average marginal effect of policy demand amounts to $-0.40[-0.52,-0.30]$, comparable in magnitude to contexts with oppositional far-right parties holding between 10 and 15 percent of seats in the national legislature. This matches closely to the strength of the seven far-right parties with government involvement included in my analysis, among which seat shares range between 4.9 and 18.6 percent with an average of 12.3 percent. Far-right parties in government thus mobilize support on policy demand to a similar extent as equally strong far-right parties in opposition. On average, their participation in national government seems to neither enhance nor jeopardize the credibility of their policy appeal. Lastly, the bottom right of Figure 1 shows that political dissatisfaction does not benefit far-right parties in government. At $-0.02[-0.05,0.00]$, the effect is substantively negligible and statistically indistinguishable from zero. This shows that, in line with my theoretical expectations, far-right parties in government jeopardize a credible appeal to dissatisfied voters. In evaluating these parties, voters rely exclusively on policy-directed considerations.

\footnotetext{
${ }^{11}$ Figure A.25 in the Online Appendix illustrates the underlying micro-logic of this finding: Strong far-right parties attract significantly more dissatisfied voters with medium policy distance than weak far-right parties, indicating that their anti-establishment appeal extends beyond the hard core of their ideological adherents.
} 
Figure 2 substantiates these findings through conditional expected values, illustrating the electoral appeal of the far right as a function of policy demand and political dissatisfaction under three contextual conditions: For weak and strong far-right parties in opposition at seat shares of 0 and 20 percent, respectively, as well as for far-right parties in government. As one can see, individual evaluations of far-right parties increase primarily as a function of congruous policy demand. When policy demand is absent, far-right parties remain essentially unattractive to voters. This holds true across all three scenarios and among politically satisfied and dissatisfied voters alike.

The electoral appeal of oppositional far-right parties without legislative representation, illustrated on the left of Figure 2, is generally limited. To the extent that these parties manage to attract voters, they do so primarily among voters who simultaneously display strong demand for the far right's policies and high political dissatisfaction. With an expected PTV of 0.33 $[0.26,0.41]$, dissatisfied individuals with far-right policy preferences consider it much more likely to vote for a far-right party than satisfied individuals at $0.20[0.14,0.26]$.

The prediction for oppositional far-right parties with a strong standing in national parliament, displayed in the center of Figure 2, reveals some notable differences. Among voters with far-right policy preferences, the expected PTV scores range from $0.41[0.31,0.53]$ among politically satisfied individuals to 0.64 [0.52, 0.77] among dissatisfied individuals. Thus, even though the nominal gap between satisfied and dissatisfied voters increases slightly as far-right parties' legislative strength increases, it turns out less important in perspective: Since strong far-right parties provide considerable strategic incentives for policy-directed voting, policy demand becomes a much more momentous driver of far-right voting vis-à-vis political dissatisfaction. Therefore, these parties manage to attract voters to a considerable extent through policy demand alone.

As expected, the picture looks different for far-right parties in government, illustrated on the right-hand side of Figure 2: Their electoral appeal collapses to a pure policy appeal. At 0.41 [0.31, 0.53 , the electoral appeal of far-right parties in government to satisfied voters with far-right policy preferences is comparable in magnitude to that found for strong oppositional far-right parties. Yet, it lacks the supplementary momentum of a credible anti-establishment appeal: Compared to strong far-right parties in opposition, far-right parties in government struggle to mobilize dissatisfied right-wing voters. The findings thus suggest that eventual electoral losses after far-right government involvement can hardly be attributed to an alienation of voters who initially agreed with the parties' policy platforms but rather to an alienation of voters who concurrently demand far-right policies and a credible anti-establishment stance.

\subsection{Robustness checks}

In order to test whether my results are sensitive to alternative specifications of the empirical analysis, I subject my findings to extensive robustness checks, all of which are detailed in the Online Appendix. These include (1) two alternative model specifications to the Tobit specification presented above, (2) replications of the main analysis accounting for party position rationalization bias, potential endogeneity of political dissatisfaction to policy demand, and the change in the measure of political dissatisfaction post-2009, (3) replications using alternative operationalizations of the contextual moderator (vote shares in the past national election, vote shares in the most recent election to the European Parliament, and pre-survey national polling averages), (4) tests of the robustness of the findings to characteristics of the competitive party landscape (other anti-establishment competitors, toughest position of mainstream competitors on the left right dimension and on issues of national identity), and (5) robustness to alternative control variable and imputation strategies. All of these tests share the same outcome variable, and therefore produce estimates that can be directly compared.

Figure 3 presents the results from the main analysis and the 13 robustness checks described above. The plot indicates that all specifications yield equivalent substantive conclusions and thereby corroborates the robustness of my findings. In addition to these tests, the Online 

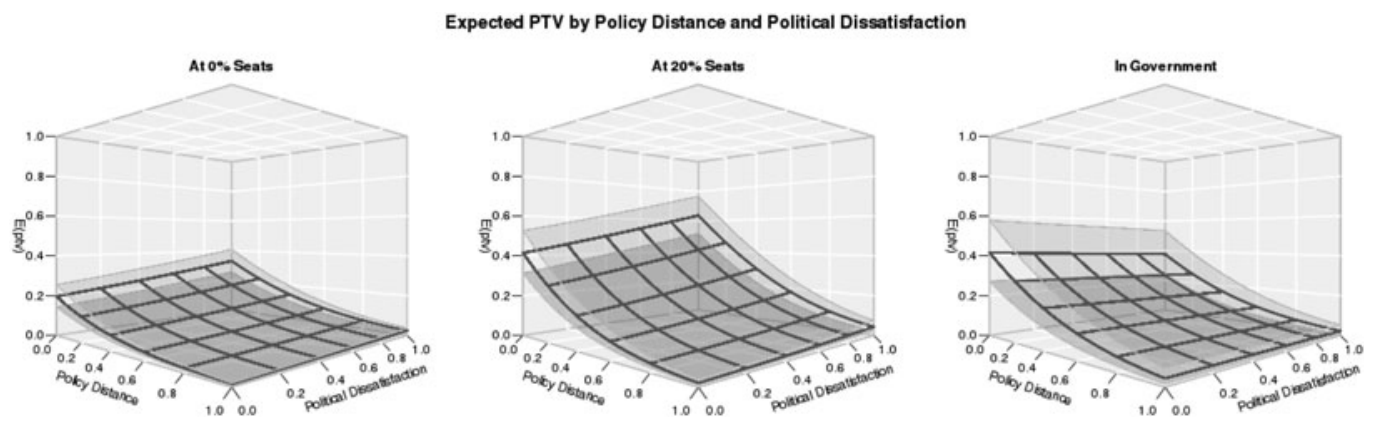

Figure 2. Expected future vote probabilities as a function of policy demand and political dissatisfaction. Note: Posterior medians and $95 \%$ posterior intervals. The first two plots report the quantity conditional on far-right seat shares of 0 and 20 percent, respectively, based on model (1). The third plot reports the quantity for far-right parties in government, based on model (2).

Appendix reports two models with different (outcome) variables. The first is a replication of the main analysis using normalized subjective vote probabilities. As an artifact of the normalization, the findings from this test, presented in Figure A.11, produce different effect magnitudes but yield the same substantive conclusions as the main analysis. The second is an analysis based on data from the European Social Survey 1-8, which is based on a vastly different sample of spatiotemporal contexts and uses different measures of the key variables: Discrete vote choice in place of subjective vote probabilities, immigration preferences in place of policy distance, and trust in politicians in place of political dissatisfaction. Despite these notable differences, the robustness checks, displayed in Figure A.16 in the Online Appendix, yields results that support the substantive conclusions drawn from the main analysis. Additional tests reported in the Online Appendix confirm the robustness of my findings under different subsets of parties of the far-right family (Figures A.7 and A.8), visualize context-specific estimates (Figures A.4-A.6), and explore the nuances of the micro-level mechanism of my argument by allowing for mutual reinforcement of the effects of policy demand and political dissatisfaction at the micro-level (Figure A.25).

\section{Summary and discussion}

The increasing and persisting electoral support for the West European far-right has motivated much research on both individual and contextual determinants of the far right vote (e.g., Van der Brug and Fennema, 2003; Carter, 2005; Arzheimer, 2008, 2009). Research that bridges the gap between individual-level demand and contextual supply, however, remains rare. This is surprising because contextual variations on the supply side, where far-right party agency unfolds within varying political environments is likely to exert systematic repercussions on individual voting behavior. In this vein, the theoretical and empirical contributions presented in this paper highlight the importance of far-right parties' past achievements for their prospects of attracting voters to the policy and anti-establishment components of their platform. My analyses show that the electoral appeal of far-right parties is strongly context-dependent. This critically advances our understanding of why these parties vary in the mode and scope of their appeal.

In line with theories of strategic voting, the empirical results show that far-right parties attract voters first and foremost by satisfying their demand for substantive policy. Policy-directed considerations dominate voters' evaluations of far-right parties generally, but considerably more so where far-right parties are strong. Furthermore, joining government neither erodes nor boosts the far right's policy appeal: Far-right parties in government mobilize policy demand to similar extents as we would expect them to do in opposition. Far-right parties also serve as vehicles for voicing dissatisfaction and protest. The anti-establishment appeal of far-right parties does not 


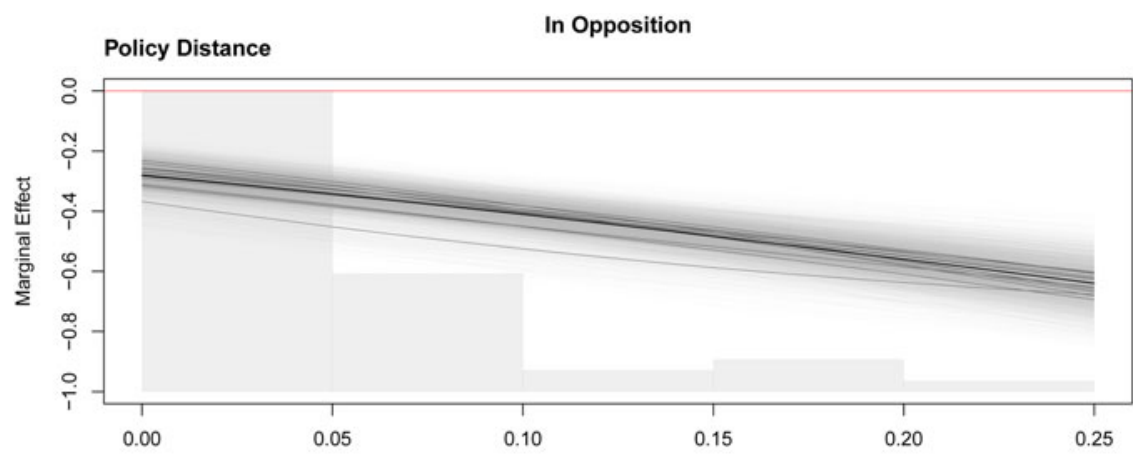

Political Dissatisfaction
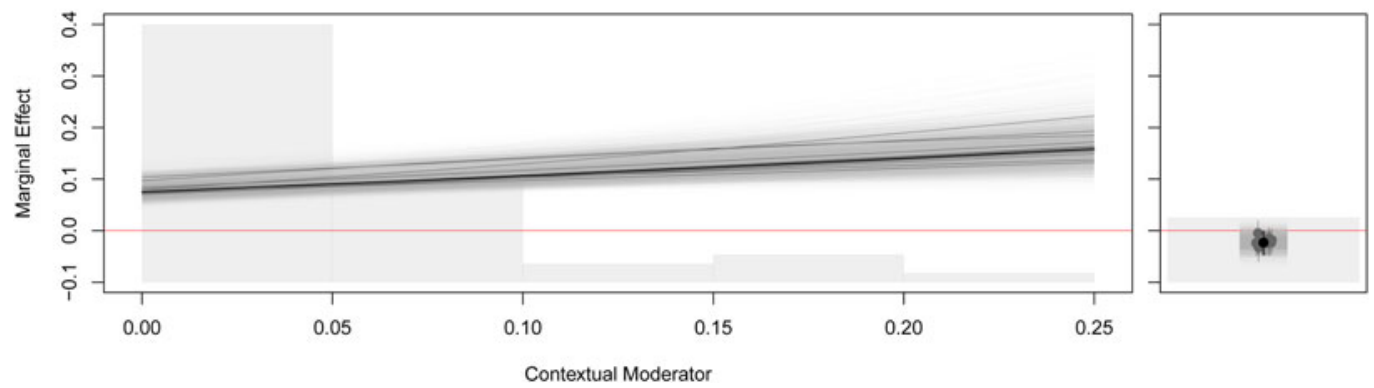

Figure 3. Average marginal effects of policy distance (political dissatisfaction) from 14 different model specifications. Note: Dark gray lines depict posterior medians. Light gray lines depict draws from the posterior distributions of the 12 model specications.

erode in any systematic fashion when they become powerful contestants in their respective party systems-unless they join the government. In opposition, far-right parties can credibly supply both policy and anti-establishment platforms. Voter behavior consequently reflects this pattern. The prevalence of far-right parties' policy appeal is thus not in and of itself sufficient for ruling out the relevance of a protest appeal. Joining government, on the other hand, jeopardizes the credibility of the far right's anti-establishment appeal and far-right parties consequently fail to rally support among the disaffected. Thereby, the broad comparative setup of my study, covering 52 electoral contexts across 11 countries and spanning a period of 25 years, provides detailed and insightful conclusions on the context-dependent micro-mechanisms that underlie far-right voting.

At the same time, my study is not without its limitations. First, few concurrences of far-right government involvement and survey field times mean that my main analysis only features seven contexts with far-right parties in government from three different countries. Thus, a broader scope in studying voting behavior for far-right parties in the government would be desirable to scrutinize the robustness of my comparison between far-right parties in government and opposition. My robustness check on the basis of ESS data takes an important step in this direction: It features 14 instances of far-right government involvement from five different countries and supports my initial conclusions. Secondly, the argument and corresponding test presented in this paper focuses on variations in voting behavior within the West European far-right party family. Testing whether the argument extends to other anti-establishment parties, e.g. to far left or neoliberal populists, and scrutinizing how the mechanisms proposed in this paper compared to voting for mainstream parties (see Van der Brug et al., 2000; Van der Brug and Fennema, 2003), present intriguing avenues for future research. 
Thirdly, the reliance on a broad spatio-temporal sample brings along an inevitable compromise: Limitations with respect to the measurement of key concepts. While my robustness check on the basis of more specific measures from the ESS 1-8 suggests that my substantive conclusions hold under different operationalizations, future research can benefit widely from the implementation of more specific measures - in particular from measures that capture different dimensions of voters' protest motives (e.g., Akkerman et al., 2013; Schumacher and Rooduijn, 2013; Rooduijn et al., 2016). It is, therefore, a welcome development that comparative survey projects such as The Comparative Study of Electoral Systems (2017) now include detailed measures of anti-establishment and populist attitudes. Similarly, strategic incentives that moderate the relevance of policy demand and protest motives remain notoriously hard to capture in a way that yields cross-nationally equivalent behavioral cues. While it supports my substantive conclusions that my findings hold under four different operationalizations of contextual incentive structures, future comparative inquiries into strategic voting could vastly benefit from the inclusion of perceptive measures of party effectiveness and party legitimacy in cross-national survey projects (see Bos and van der Brug, 2010; Bos et al., 2011).

Future research along these lines can significantly increase our understanding of both voting behavior and electoral outcomes in Western democracies. As the argument and findings presented in this paper show, political contestation in Western democracies cannot be understood solely within the confines of issue competition in single or multiple dimensions. The many recent successes of anti-establishment parties, campaigns, and candidates, in Western Europe and beyond, underline that these explanations should be studied in conjunction with anti-establishment attitudes and strategic incentives.

Author ORCIDs. (D) Denis Cohen, 0000-0002-8978-8249.

Acknowledgments. I thank Heike Klüver, Tarik Abou-Chadi, Christopher Wratil, Till Weber as well as two anonymous reviewers and PSRM Associate Editor Simon Hug for helpful comments and suggestions. Previous drafts of this paper were presented at the 2017 EPSA Conference and in the Comparative Politics and Comparative Political Behavior colloquia at Humboldt University of Berlin.

Supplementary Material. The supplementary material for this article can be found at https://doi.org/10.1017/psrm.2019.21

\section{References}

Afonso A (2015) Choosing whom to betray: populist right-wing parties, welfare state reforms and the trade-off between office and votes. European Political Science Review 7, 1-22.

Akkerman T and De Lange SL (2012) Radical right parties in office: incumbency records and the electoral cost of governing. Government and Opposition 47, 574-596.

Akkerman A, Mudde C and Zaslove A (2013) How populist are the people? Measuring populist attitudes in voters. Comparative Political Studies 47, 1324-1353.

Art D (2011) Inside the Radical Right. Cambridge: Cambridge University Press.

Arzheimer K (2008) Protest, neo-liberalism or anti-immigrant sentiment: what motivates the voters of the extreme right in Western Europe? Zeitschrift für Vergleichende Politikwissenschaft 2, 173-197.

Arzheimer K (2009) Contextual factors and the extreme right vote in Western Europe, 1980-2002. American Journal of Political Science 53, 259-275.

Bos L and van der Brug W (2010) Public images of leaders of anti-immigration parties: perceptions of legitimacy and effectiveness. Party Politics 16, 777-799.

Bos L, van der Brug W and de Vreese C (2011) How the media shape perceptions of right-wing populist leaders. Political Communication 28, 182-206.

Carter E (2005) The Extreme Right in Western Europe. Success or Failure? Manchester, New York: Manchester University Press.

Cox GW (1997) Making Votes Count. Strategic Coordination in the World's Electoral Systems,vol. 340. Cambridge: Cambridge University Press.

De Lange SL (2012) New alliances: why mainstream parties govern with radical right-wing populist parties. Political Studies 60, 899-918.

Downs A (1957) An Economic Theory of Democracy. New York, NY: Harper. 
Enelow JM and Hinich MJ (1984) The Spatial Theory of Voting: An Introduction. New York: Cambridge University Press.

Fennema M (1997) Some conceptual issues and problems in the comparison of anti-immigrant parties in Western Europe. Party Politics 3, 473-492.

Franklin M and De Sio L (2012) Party matters: the surprising role of party characteristics in conditioning the bases of electoral support in Europe. Paper prepared for presentation at the American Political Science Association annual meeting, August 2012.

Grofman B (1985) The neglected role of the status quo in models of issue voting. Journal of Politics 47, $230-237$.

Heinisch R (2003) Success in opposition-failure in government: explaining the performance of right-wing populist parties in public office. West European Politics 26, 91-130.

Ivarsflaten E (2008) What unites right-wing populists in Western Europe? Re-examining grievance mobilization models in seven successful cases. Comparative Political Studies 41, 3-23.

Meguid BM (2005) Competition between unequals: the role of mainstream party strategy in niche party success. American Political Science Review 99, 347-359.

Mudde C (2007) Populist Radical Right Parties in Europe. Cambridge: Cambridge University Press.

Mudde C (2010) The populist radical right: a pathological normalcy. West European Politics 33, 1167-1186.

Norris P (2005) Radical Right. Voters and Parties in the Electoral Market. Cambridge: Cambridge University Press.

Rooduijn M, de Lange SL and van der Brug W (2014) A populist Zeitgeist? Programmatic contagion by populist parties in Western Europe. Party Politics 20, 563-575.

Rooduijn M, Van der Brug W and de Lange SL (2016) Expressing or fuelling discontent? The relationship between populist voting and political discontent. Electoral Studies 43, 32-40.

Schumacher G and Rooduijn M (2013) Sympathy for the "devil"? Voting for populists in the 2006 and 2010 Dutch general elections. Electoral Studies 32, 124-133.

Stan Development Team (2016) Stan: the R interface to Stan. R package version 2.14.1.

The Comparative Study of Electoral Systems (2017) CSES Module 4 Fourth Advance Release [dataset].11 April, 2017 version.

Tillie J (1995) Party Utility and Voting Behavior. Amsterdam: Het Spinhuis.

Van der Brug W and Fennema M (2003) Protest or mainstream? How the European anti-immigrant parties developed into two separate groups by 1999. European Journal of Political Research 42, 55-76.

Van der Brug W, Fennema M and Tillie J (2000) Anti-immigrant parties in Europe: ideological or protest Vote? European Journal of Political Research 37, 77-102.

Van der Brug W, Fennema M and Tillie J (2005) Why some anti-immigrant parties fail and others succeed: a two-step model of aggregate electoral support. Comparative Political Studies 38, 537-573.

Van der Eijk C, van der Brug W, Kroh M and Franklin M (2006) Rethinking the dependent variable in voting behavior-on the measurement and analysis of electoral utilities. Electoral Studies 25, 424-447.

Van Hauwaert S and van Kessel S (2018) Beyond protest and discontent. A cross-national analysis of the effect of populist attitudes and issue positions on populist party support. European Journal of Political Research 57, 68-92.

Van Kessel S (2015) Populist Parties in Europe: Agents of Discontent? Houndmills, Basingstoke, Hampshire, London: Palgrave MacMillan.

Van Spanje J (2010a) Contagious parties: anti-immigration parties and their impact on other parties' immigration stances in contemporary Western Europe. Party Politics 16, 563-586.

Van Spanje J (2010b) Parties beyond the pale: why some political parties are ostracized by their competitors while others are not. Comparative European Politics 8, 354-383.

Van Spanje J (2011) Keeping the rascals in: anti-political-establishment parties and their cost of governing in established democracies. European Journal of Political Research 50, 609-635.

Van Spanje J and Azrout R (2018) Tainted love: how stigmatization of a political party in news media reduces its electoral support. International Journal of Public Opinion Research. First published in March 2018.

Wagner M and Meyer TM (2017) The radical right as niche parties? The ideological landscape of party systems in Western Europe, 1980-2014. Political Studies 65, 84-107.

Weber T (2015) Synergy in spatial models of voting: how critical cases show that proximity, direction and discounting are friends, not foes. Journal of Elections. Public Opinion and Parties 25, 504-529.

Zaslove A (2012) The populist radical right in government: the structure and agency of success and failure. Comparative European Politics 10, 421-448.

Cite this article: Cohen D (2020). Between strategy and protest: how policy demand, political dissatisfaction and strategic incentives matter for far-right voting. Political Science Research and Methods 8, 662-676. https://doi.org/10.1017/ psrm.2019.21 